Lepr. Rev. (1972) 42, 255-259

\title{
The Ninth Meeting of the Indian Association of Leprologists and Twelfth All-India Leprosy Workers' Conference Held at Bhopal, Madhya Pradesh*
}

\author{
T. FRANK DAVEY \\ Victoria Hospital, Dichpalli, \\ Andhra Pradesh, India
}

INTRODUCTION

A well-known map showing leprosy prevalence throughout the world paints some countries black. India, along with some other countries, appears a dull shade of grey, and the impression gained by the inexperienced observer could well be that leprosy in India is less important a problem than it is, for instance, in Nigeria. Such an impression is grossly in error. World maps of leprosy prevalence have little virtue unless they are considered side by side with the actual numbers of people infected and at risk, and with the fact that leprosy is not a disease of uniform severity the world over.

With an estimated $2 \frac{1}{2}$ million sufferers, India may well have more people at risk of contracting leprosy than any other nation in the world. Furthermore, in India every problem in leprosy seems to present itself in its most acute and difficult form. The nature of the disease, its persistence, its disabling effects, and its social and psychological consequences all combine to give leprosy in India a particular importance. The small army of dedicated workers, while certainly inadequate to bring the disease under control, have given much thought over the years to the problems of leprosy and its control, and many ideas and no little wisdom are the result. The experience of leprosy workers in India is thus of interest and significance to leprosy workers everywhere.

The 9th Meeting of the Indian Association of Leprologists and the 12th All-India Leprosy Workers' Conference took place at Bhopal between 24 and 29 October, 1971, at the invitation of the State Government of Madhya Pradesh. The occasion followed the well-established tradition, so aptly expressing Indian concepts of democracy, that leprosy workers of all types and levels were welcome. The presence of large numbers of paramedical and social workers, on whom falls the brunt of fighting leprosy at ground level, was an important feature. While sitting respectfully during the scientific sessions of the Indian Association of Leprologists' Meeting, they came into their own during the Leprosy Workers' Conference, and contributed to this latter a concern with basic practical issues which was very important.

* Received for publication 20 December, 1971. 


\section{The Leprologists}

The 9th Biennial Conference of the Indian Association of Leprologists met first, under the distinguished Presidency of Dr V. P. Das, and was inaugurated by Shri Shyama Charan Shukla, Chief Minister, Madhya Pradesh. As papers and discussions presented at the scientific sessions will in due course appear in Leprosy in India, only a brief summary is indicated here, drawing attention to points of general interest and scientific progress.

\section{Epidemiology and Control}

The long tradition of epidemiological study founded by Lowe and Dharmendra in the 1930's continues to find expression at each succeeding conference. There are particular difficulties in the way of securing data of statistical significance in the Indian rural setting. Some interesting figures regarding leprosy incidence in an area covered by substantial leprosy control work were given in the paper by Drs P. S. S. Rao, A.B.A. Karat and Mrs Karat on estimates of the incidence of leprosy in Gudiyatham Taluk. In this area, with a total population of 400,000 , the population survey was complete and all known cases of leprosy registered by 1966. During 1967-69 the number of new cases registered was 1922, giving an annual incidence rate of 0.8 per 1000 , a lepromatous rate of $6 \%$, and male : female and adult : child ratios of $1: 1$. These rates come much closer to the findings in other countries than do some others reported, but the incidence found gives little ground for complacency. Dr P. N. Neelan reported on relapse in lepromatous leprosy under sulphone treatment in rural conditions. As may be expected, the maximum risk of relapse occurred during the first 3 years after bacterial negativity; over a 10-year period, the figure was $1.9 \%$ per year among 2833 patients. This is not very significant, as in India bacterial negativity is often achieved only after long periods of treatment, and intermittent treatment is all too common; a finding of $3.3 \%$ relapse per year among 151 patients known to have taken irregular treatment is of more concern.

Dr S. K. Noordeen drew attention to the frequency of mono- and poly-neuritic leprosy, which he found in one-sixth of all cases detected. A lower limb was involved more frequently than an upper, and spontaneous regression of nerve lesions was quite common.

\section{Surgical Aspects}

India is proud of her pioneering rôle in reconstructive surgery in leprosy, and a whole session of the Conference was devoted to this aspect. Dr Srinivasan reported on a new corrective procedure for claw hand, described as an Extensor Diversion Graft Operation. The management of the paralysed thumb was discussed by Professor A. J. Salvapandian, including a new method of assessing the degree of thumb-web contracture, and new modifications in procedures for restoring the function of the paralysed thumb. Dr Ranney reported on a post-operative study of temporalis transfer for the relief of lagophthalmos in leprosy patients.

Reconstructive surgery in leprosy has now been accepted by surgeons in various parts of India as a legitimate challenge to their skill and ingenuity. We are now far removed from the days when one or two pioneers in this field held a leprosy 
workers' conference enthralled as they opened up new vistas of hope to patients. This session could easily have taken place in a conference of orthopaedic and plastic surgeons, and there seems little doubt that with increasing sophistication that would be the right setting for the exposition and discussion of new surgical procedures, now that the basic principles and standard practice have become widely recognized.

The open forum led by Dr T. F. Davey on "Problems of therapy, with special reference to reactional states and sulphone resistance" evoked much useful discussion. The following points were made:

(1) In India only a minority of lepromatous patients are of the anergic LL varisty. The dominant type is the type designated by Ridley as LI, in which an earlier dimorphous type of response has broken down, not necessarily permanently or completely. This is potentially an unstable form of leprosy, very reaction-prone, and frequently presenting very severe nerve involvement.

(2) The response of these patients to dapsone treatment tends to be slower than is usual elsewhere. Whereas it was expected in Nigeria that with good chemotherapy the Morphological Index would fall below 10\% within 6 months, this is exceptional in central India, and often at least one year is needed to achieve this result.

(3) Chemotherapy with dapsone thus needs to be very prolonged. As yet we have not the basic in vivo data to establish that drug resistance to dapsone exists in India, but there is strong clinical evidence that it does. Many patients respond to quite low doses of dapsone (e.g., $30 \mathrm{mg}$ per week) just as well as they do to the high doses still widely used (600 mg per week). Cases have been encountered in which after many years of high-dose dapsone therapy, fresh exacerbation has occurred. It seems wise, as routine, to aim at a maintenance dose which is calculated to be effective against partially resistant bacilli and, as suggested by Rees, a figure of $300 \mathrm{mg}$ per week appears reasonable. There are no logical grounds for intermittent treatment-indeed this could contribute to the development of drug resistance. Once initiated, chemotherapy should be regular and persisted with for long periods. A negative skin smear is an artificial criterion for stopping chemotherapy. Apart from its intrinsic unreliability as an index that the infection has come to an end, the skin smear, because of the limitation of its technique, can never reveal the situation in muscles which can be reservoirs of the bacillus. The patient needs to accept that chemotherapy must be continued for life if he has suffered from lepromatous leprosy.

(4) Reaction in India takes several forms, some of which are not clearly understood. We need to remember that ery thema nodosum leprosum (ENL) is not necessarily always induced by dapsone. More than 30 precipitating causes of ENL are known, and quite a number of these are operative in India. We should not incriminate dapsone as the cause of this complication until we have considered the other bacterial, viral, fungal, chemical, metabolic, and psychological factors which may be determinative factors.

(5) Too hasty recourse to corticosteroids in cases of reaction is to be deplored. Corticosteroids certainly have their place in acute types of reaction, especially where antimony preparations have no immediate effect. Where there is an underlying cause, we must obviously treat it. Nowadays we have in clofazimine (Lamprene, or B 663) a much more valuable remedy for reactional states, not only for controlling reaction, but as on-going chemotherapy for patients who 
cannot tolerate dapsone. What is now urgently needed is the manufacture and distribution of clofazimine in India at a price the average patient can afford.

The remaining sessions of the conference had to be curtailed as some of those presenting papers could not be present. Dr Job gave a scholarly paper on the ultra-structural study of nerve lesions. Dr Parikh described leprosy lesions on the scalp. Dr Desikan described the distribution of $M y c o$. leprae in various structures, Dr Pandya discussed "Electrodiagnostic aids in the differential diagnosis of leprosy", and Dr Ghosh spoke on "Leprosy and tuberculosis", while a range of papers covered other topics. Altogether, the Conference proved to be a useful forum for the sharing of experience and provided a meeting point for leprologists who in this large country of ten have little opportunity to meet one another.

\section{The Leprosy Workers}

In an outstanding Presidential address at the opening of the Twelfth All-India Leprosy Workers' Conference, Professor T. N. Jagadisan referred to the "disenchantment" that had come from expecting too much of the sulphones. "Unfortunately, over-enthusiasm led to over-simplification and there was an all-round expectation that through widespread administration of sulphones leprosy will quickly disappear. But it soon became apparent that the organization of control campaigns was not a soulless reaching out of drugs, but a complex, dynamic process in which many human factors were involved." He insisted that any leprosy control programme that ignores the felt need of the individual patient is doomed to failure, and pleaded for a whole view of the leprosy problem, which does not lose sight of the patient in its concern for the community.

The Conference addressed itself to three topics:

(a) Integration of leprosy control with the general medical and health services; (b) Health education for leprosy control; (c) Social and administrative aspects in relation to rehabilitation.

\section{A. The Integration of Leprosy Control with General Medical and Health Services}

This is an issue of universal interest. In some countries, leprosy has already been absorbed into the planning and practice of the general health services. India, along with some other countries, is not yet at this point of development. While all acknowledge the desirability of freeing leprosy from its peculiar significance as quickly as possible, there is real danger that precipitate action, taken before the general public are ready for it, could put the clock back by decades and cause tremendous suffering to patients. The subject was discussed at length, and a memorandum prepared by an expert committee, and addressed to the Government, was endorsed by the full conference. It is worth quoting in full, and appears as an appendix to this report (see p. 260).

\section{B. Health Education for Leprosy Control}

Much has been written in recent years on the importance of health education of the public where leprosy is concerned, and the rehabilitation of leprosy sufferers into the community. The two themes are intimately related. Behind all the problems of leprosy control and the care of patients, there broods the evil 
angel of public prejudice against leprosy sufferers, and prejudice can only succumb to the enlightenment which effective health education can bring. The problem is not one of principle but of method. Where both health education and rehabilitation are concerned, we have guidance galore. What we lack is the means of effectively changing public opinion. We cannot expect more rapid progress in India than, say, in Britain in this respect. Where leprosy is concerned, prejudice dies extremely hard, whatever the form of the society involved in it. Until the truth is presented convincingly and consistently over the mass media of communication we can expect very little progress.

This is very much the case where India is concerned. Among the hundreds of millions of people in rural society the impact of the mass media is as yet minimal, and prejudice is likely to persist for a long time. In the cities, where the level of literacy is higher, and rapid social change is reducing the bastions of caste, progress could be much more rapid, but it is as yet making little headway. In Bombay, a private group of concerned professional men has made a promising entry into radio, with a regular and popular feature designed to present the truth about leprosy. Here is a noteworthy example of what can be done, but it needs widespread emulation.

In the Conference session on Health Education, these issues were recognized. Emphasis was laid on the importance of recruiting the practical interest of professional groups, and the importance of the urban situation as a point where progress could be hoped for fairly speedily, was emphasized.

\section{Administrative and Social Aspects, including Rehabilitation}

This session covered several points of interest.

The first paper, by G. S. Dalmia on "The changing pattern of leprosy institutions" gave welcome recognition to the place of leprosy institutions in a comprehensive national leprosy control programme. Experience in India has confirmed the importance of this. We may cope with leprosy on a domiciliary and outpatient basis to a large extent, but patients from time to time have real and urgent needs for the degree of medical care which can only be given on a hospital and residential basis. In the present situation, some specialist institutions are necessary if patients are not to be treated as second-class citizens.

The theme of the psychological rehabilitation of leprosy patients was taken up by Dr Davey in a paper which evoked much discussion.

Papers by S. W. Gokhale, Smt. Indumati, S. Rao and P. S. Damie all pinpointed and stressed the need in rehabilitation programmes not to treat our patients as a socially isolated group, but to integrate them with wider groups of the physically disabled. 